\title{
BASE NACIONAL COMUM CURRICULAR DE CIÊNCIAS: INTERSEÇÕES ENTRE CURRÍCULO, DOCÊNCIA E FORMAÇÃO DE PROFESSORES
}

\author{
COMMON CURRICULAR NATIONAL BASE: INTERSECTIONS BETWEEN CURRICULUM, \\ TEACHING AND TEACHER TRAINING
}

https://orcid.org/0000-0003-1946-5345 Franco Gomes Biondo ${ }^{\mathrm{A}}$ https://orcid.org/0000-0002-0765-7852 Maria Matos ${ }^{B}$ https://orcid.org/0000-0002-7134-6119 Carla Mendes Maciel ${ }^{\text {C }}$ https://orcid.org/0000-0002-4566-5730 Natalia Tavares Rios D

\begin{abstract}
${ }^{\text {A }}$ Faculdade de Formação de Professores da Universidade do Estado do Rio de Janeiro (FFP/UERJ), São Gonçalo, RJ, Brasil ${ }^{\text {в }}$ Colégio de Aplicação da Universidade Federal do Rio de Janeiro (CAP-UFRJ), Rio de Janeiro, RJ, Brasil ${ }^{\mathrm{C}}$ Colégio de Aplicação da Universidade Federal do Rio de Janeiro (CAP-UFRJ), Rio de Janeiro, RJ, Brasil ${ }^{\mathrm{D}}$ Colégio de Aplicação da Universidade Federal do Rio de Janeiro (CAP-UFRJ), Rio de Janeiro, RJ, Brasil
\end{abstract}

\section{Resumo}

Este texto é produto de um projeto de extensão desenvolvido pelo Colégio de Aplicação da UFRJ e vinculado ao Complexo de Formação de Professores da universidade. Situamos o projeto como uma iniciativa que fomenta o debate teórico-prático do ensino de Ciências e Biologia e a coletividade docente e relatamos nossa ação de 2019, voltada à discussão dos impactos da Base Nacional Comum Curricular e realizada em parceria com uma escola municipal vinculada ao Complexo. Em seguida, apontamos o aspecto regulatório da Base Nacional Comum da Formação de Professores da Educação Básica. Argumentamos que uma forma de adaptação crítica a esse contexto consiste em fomentar a identificação dos licenciandos como futuros agentes de refração curricular, autores cotidianos dos conhecimentos escolares.

Palavras-chave: Extensão; Política curricular; BNCC; BNCFP; Ensino de Ciências.

\begin{abstract}
This text is a product of an outreach project developed by the UFRJ Application School and linked to the university's Teacher Training Complex. It is an initiative that fosters teaching collectivism and the theoretical and practical debate of Science and Biology education. Then, we report our 2019 action, aimed at discussing the impacts of the Common Curricular National Base on teaching, carried out in partnership with a municipal school linked to the Complex. In a third moment, we point out the regulatory aspect of the Common National Base of Teacher Training for Basic Education. We argue that a form of critical adaptation to this context consists of promoting the identification of graduates as future agents of curricular refraction, daily authors of school knowledge.
\end{abstract}

Keywords: Outreach; Curricular policy; BNCC; BNCFP; Science education. 


\section{Introdução}

Este texto busca refletir sobre alguns desdobramentos da Base Nacional Comum Curricular (BNCC) nas práticas e nas atividades docentes, tanto na educação básica quanto na formação de professores. Tais reflexões apontam possíveis caminhos cotidianos de apropriação e reformulação da BNCC, que, em 2020, esteve em fase de implementação obrigatória em todas as escolas do país para a Educação Infantil e o Ensino Fundamental (EF) ${ }^{\mathrm{i}}$.

Para tal, inicialmente caracterizamos o projeto de extensão "Compartilhando Boas Práticas de Ensino de Ciências e Biologia entre Escolas Públicas”, desenvolvido pelo Setor Curricular de Ciências Biológicas do Colégio de Aplicação da Universidade Federal do Rio de Janeiro (CAp/UFRJ) e vinculado ao Complexo de Formação de Professores (CFP) desta universidade. Descrevemos, então, as ações realizadas a fim de fomentar o diálogo sobre a BNCC com professoras de outra instituição de Educação Básica, buscando fortalecer as coletividades docentes. No tópico seguinte, trazemos as impressões e questões levantadas pelas professoras participantes nos encontros realizados no âmbito do projeto. Por fim, levantamos algumas considerações sobre as limitações impostas pela encenação ${ }^{\mathrm{ii}}$ da BNCC no cotidiano das práticas docentes e sobre alguns aspectos da formação de professores que, em nossa concepção, precisam ser especialmente valorizados como adaptação crítica a esse contexto.

\section{O projeto de extensão e a formação de professores}

O Projeto "Compartilhando Boas Práticas de Ensino de Ciências e Biologia entre Escolas Públicas" é uma iniciativa de extensão que tem como objetivo estreitar os vínculos entre professores dessas disciplinas escolares de diferentes escolas públicas do estado do Rio de Janeiro. Em atuação desde 2016, vem formando uma rede de coletividade docente, incluindo professores das redes públicas de ensino - municipais, estadual e federal - e estudantes de Licenciatura em Ciências Biológicas de duas universidades públicas federais.

As ações do grupo buscam aprofundar a discussão teórico-prática de temas relacionados ao ensino de Ciências e Biologia e propor estratégias didáticas que possam ser desenvolvidas em diferentes contextos escolares. Os temas de discussão, de natureza interdisciplinar, surgem a partir de problemas enfrentados pelos docentes em seus cotidianos. A partir das reflexões levantadas, desenvolvemos possibilidades de ações críticas, considerando o panorama social, cultural e político de atuação de cada professor. A partir da coletividade docente, valorizada na discussão dos cotidianos escolares e na idealização de propostas pedagógicas, consideramos que o projeto contribui para o fortalecimento da educação pública. 
Entendendo que as ações do grupo também favorecem a ampliação de diálogo entre a formação inicial e a formação continuada de professores, em 2019 o projeto vinculou-se ao CFP. Trata-se de uma política institucional de formação de professores da UFRJ, cujo regimento foi aprovado no final de 2018 e algumas de suas ações foram implementadas em 2019. O CFP busca articular ambas as instâncias da formação docente, visando a afirmação de uma cultura docente profissional e o protagonismo dos professores da Educação Básica na formação inicial de futuros professores. Essa política é caracterizada pela parceria entre diferentes instituições e redes públicas de educação na cidade do Rio de Janeiro e pela pluralidade na participação dos sujeitos envolvidos: estudantes, professores e gestores que atuam na Educação Básica e/ou Ensino Superior (UFRJ, 2018; GABRIEL, 2019).

Três princípios básicos orientam o CFP: horizontalidade, pluralidade e integração. A horizontalidade de responsabilidades e saberes aponta que as instituições e redes parceiras são corresponsáveis pela elaboração e gestão dos planos de trabalho de forma que saberes produzidos e mobilizados em diversos espaços institucionais e profissionais sejam legitimados. Essa pluralidade propõe que as atividades do Complexo sejam planejadas e desenvolvidas com a participação de docentes, estudantes e gestores das instituições parceiras, assim como desenvolvidas em diferentes lugares de formação, que incluem as escolas, universidades e outros espaços educativos, como museus. No que tange à integração, esta deve ser promovida entre diferentes atividades nas instituições parceiras, devendo-se preservar as particularidades de cada contexto. Nesse sentido, todos os sujeitos participantes contribuem com conhecimentos e práticas inerentes aos locais de atuação (NÓVOA, 2017).

Entendemos que nossas ações no projeto de extensão se alinham aos princípios dessa política, sobretudo no que tange à aproximação entre licenciandos e professores de redes distintas. De modo a fortalecer essa relação, estabelecemos uma parceria com uma escola municipal participante do projeto piloto do CFP, para que, a partir de reuniões com as professoras de Ciências da escola, pudéssemos conduzir as ações do projeto. Nesses encontros, a principal inquietação apresentada pelas professoras consistiu no atual contexto de encenação da BNCC. Assim, o tópico seguinte detalhará a dinâmica dessas reuniões e a confluência da demanda das professoras com o contexto curricular da escola onde atuamos.

\section{Desafios da BNCC para a docência}

Nossas atividades sobre a BNCC tiveram uma motivação dupla: a demanda apresentada pelas professoras da escola municipal e o contexto da escola onde atuamos, o CAp/UFRJ. Com a efetivação obrigatória da BNCC em 2020, o coletivo docente e a direção de nossa escola 
decidiram dedicar o tema da maior parte das plenárias pedagógicas de 2019 ao currículo, debatendo nossas reflexões e posicionamentos sobre a BNCC e as formas pelas quais esta pode ser praticada de modo que a identidade curricular da instituição seja preservada. Essa identidade passa pelo entendimento de que viemos nos construindo como uma escola pública, democrática e socialmente referenciada. Nesse sentido, buscamos uma formação crítica e de acordo com os contextos culturais e sociais nos quais a comunidade escolar está inserida, tanto nas ações com estudantes da Educação Básica quanto na formação inicial e continuada de professores.

Refletindo sobre essas questões em nosso setor curricular, realizamos reuniões para ler e debater a BNCC do Ensino Fundamental II (EFII) e alguns textos de autores dos campos do Currículo e do Ensino de Ciências e Biologia. Inicialmente, avaliamos os conteúdos e as habilidades relativas à disciplina escolar Ciências para todos os anos de escolaridade do EFII (BRASIL, 2017). Também nos debruçamos sobre a parte introdutória do documento, na qual são apresentados os princípios e a perspectiva de educação adotados (BRASIL, 2017). Quanto aos textos acadêmicos da etapa seguinte, debatemos um ensaio sobre o contexto, os significados e os efeitos regulatórios da BNCC (BIONDO, 2019) e um artigo que aponta impactos considerados negativos da BNCC no ensino de Ciências (FRANCO; MUNFORD, 2018).

De modo paralelo, tivemos duas reuniões com as professoras de Ciências da escola municipal parceira do CFP. Em ambos os encontros, a partir de uma apresentação de slides, debatemos a noção de currículo nacional, o contexto político da BNCC e suas implicações nos currículos escolares, nos materiais didáticos e na formação de professores. Na dinâmica construída, o debate foi interpelado por considerações teóricas e práticas, relacionadas à atuação - nossa e delas - em sala de aula. No final do segundo encontro, fizemos um exercício de flexibilizar os sentidos valorizados na BNCC de Ciências do sexto ano, focando na unidade temática "Matéria e Energia", com o objetivo de apontar os limites pedagógicos da Base e verificar as possibilidades de contextualização curricular cotidiana.

A partir dessas iniciativas, - análise da BNCC, debate de textos acadêmicos sobre a temática e discussão com as professoras da escola municipal - decidimos socializar e desenvolver algumas reflexões. Em primeiro lugar, enfatizamos a regulação sofisticada e concatenada promovida pela BNCC sobre os currículos e os materiais didáticos. Isto ficou evidente a partir de nossa leitura sobre o documento da Base e os textos aqui mencionados, assim como de algumas falas das professoras. Por exemplo, ao serem perguntadas sobre o processo de escolha dos livros didáticos a serem adotados em 2020, elas disseram que haviam decidido por exemplares que mais se alinhavam à BNCC. Isto se deu por conta de um motivo 
principal: face às avaliações em larga escalaiii, optar por um livro que dialogasse de forma menos evidente com a BNCC seria, em suas palavras, um "tiro no pé".

Na rede municipal onde atuam, as avaliações externas do EFII são formuladas com base nos livros didáticos e em apostilas, confeccionadas pela própria Secretaria Municipal de Educação do Rio de Janeiro (SME/RJ) e distribuídas aos estudantes e aos docentes. As professoras afirmaram que o uso do livro e da apostila precisa ocorrer principalmente por esse motivo, mas, ao mesmo tempo, indicaram que outros livros e materiais são usados, de modo a enriquecer e pluralizar as discussões desenvolvidas em sala de aula. Em nossa concepção, essa fala indica uma autocompreensão por parte dessas professoras como profissionais da educação que, apesar de dialogarem com os materiais curriculares obrigatórios que são fornecidos, os utilizam e complementam a seu próprio modo, empregando seus conhecimentos para tomar decisões cotidianas que ressignificam, de alguma forma, a prescrição curricular.

Essas formas de utilização - autorais e capazes de criar sentidos não originalmente previstos ou valorizados no produto a ser usado - nos aproxima da discussão de Certeau (2014) sobre as táticas. O autor argumenta que, nas instituições sociais, existem regras pré-produzidas destinadas ao consumo por parte dos coletivos e dos sujeitos que as compõem e habitam. No entanto, esse consumo, ao invés de se restringir a uma natureza passiva de alinhamento à disciplina, pode se configurar em uma antidisciplina na medida em que as normas são consumidas de maneiras singulares. Tais maneiras estabelecem uma produção secundária de sentidos a partir daquelas regras, nas quais, por meio de movimentos de tática, as estratégias valorizadas pela instituição - no caso, os sentidos curriculares priorizados na BNCC - são contestadas, em maior ou menor grau.

No entanto, as professoras também afirmaram que os resultados nas avaliações externas determinam a posição de cada unidade escolar nos ranqueamentos da rede, nos quais elas indicaram que a escola onde trabalham tradicionalmente alcança posições elevadas. Em nossa interpretação, isso revela um possível status da unidade escolar que, em prol de eventuais gratificações e/ou investimentos estruturais, precisa ser zelado e mantido por toda a comunidade escolar. É nesse sentido que a ressignificação curricular que argumentamos acima parece ter como limite as avaliações externas: os conteúdos cobrados por esses testes devem ser abordados em momentos anteriores a cada período avaliativo, sujeitos à maneira mais autoral e criativa que o docente tenha encontrado dentro desse cronograma fixo.

Destacamos que a ressignificação curricular cotidiana fica limitada pela maneira como o sistema educacional se organiza nas escolas da rede, de acordo com a lógica da avaliação externa como forma de controle do trabalho docente. Saviani (2014) traz essa discussão em 
uma produção na qual argumenta a favor de um sistema nacional de educação, que, em sua visão, deve ser integrado, organizado, coletivo e pautado na teoria educacional. É a partir desse último fator que o autor tece uma crítica às avaliações em larga escala, a partir das quais "todos os níveis e modalidades de ensino estão organizando-se em função do êxito nas provas buscando aumentar um pontinho no Índice de Desenvolvimento da Educação Básica (Ideb)” (p. 40). Assim, a teorização pedagógica, que estimula a avaliação processual ${ }^{\mathrm{iv}}$ e que considera as especificidades de docentes, estudantes e escolas, é deixada de lado em nome da conversão de “todo o 'sistema de ensino' numa espécie de grande 'cursinho pré-vestibular'” (SAVIANI, 2014, p. 39-40).

No diálogo com as professoras, discutimos que, em nossa escola, escolhemos um livro didático que se aproximasse do currículo que viemos desenvolvendo nos últimos anos, embora menos próximo à BNCC. Refletimos sobre como isso ainda era possível porque o controle sobre nosso trabalho não era tão intenso, face à autonomia universitária, visto que o Colégio de Aplicação é um órgão suplementar do Centro de Filosofia e Ciências Humanas $(\mathrm{CFCH})$ da UFRJ. A liberdade de cátedra e a autonomia de gestão administrativa, financeira e patrimonial da universidade pública são preceitos constitucionais do Brasil e defendidos por pesquisadores em educação como fundamentais para garantia da legitimidade científica dessas instituições e sua relação com a formação humana (LEHER, 2019). Embora a autonomia universitária esteja cada vez mais ameaçada por questões orçamentárias e de intervenções governamentais (LEHER, 2019), ainda encontramos espaços de resistência na universidade que nos permitem organizar nosso fazer cotidiano com maior soberania que em escolas públicas de outras esferas.

Outra questão trazida pelas professoras da escola da rede nos nossos encontros foi a falta de planejamento face à efetivação da BNCC. As docentes afirmaram que não há um plano de transição entre a proposta curricular vigente e aquela prevista pela BNCC para estudantes que já iniciaram o EF. Assim, para esses estudantes, alguns conteúdos das disciplinas escolares, incluindo Ciências, seriam repetidos e, outros, perdidos. Entendemos que a ausência de um plano de transição curricular desconsidera as trajetórias formativas dos diferentes estudantes e evidencia o distanciamento entre a $\mathrm{BNCC}$ e a realidade escolar cotidiana. O levantamento dessa questão pelas professoras endossa nossa compreensão dessas profissionais como produtoras de conhecimentos escolares e curriculares, produzidos a partir da docência experienciada no "chão da escola" e que refletem o comprometimento com processos pedagógicos imbricados à formação de cada estudante. 


\section{A BNC da formação de professores}

Tendo desenvolvido alguns dos impactos da BNCC na docência, nesta seção iremos tecer algumas reflexões referentes aos desdobramentos na formação de professores. Para isso, iremos dialogar com algumas produções acadêmicas que problematizam o documento publicado pelo Ministério da Educação (MEC) em 2018, intitulado Base Nacional Comum da Formação de Professores da Educação Básica (BNCFP) (BRASIL, 2018).

Em primeiro lugar, consideramos pertinente fazer referência ao contexto neoliberal e neoconservador do cenário sociopolítico global atual, gerando impactos em diversos setores da sociedade, incluindo a educação e, consequentemente, as políticas curriculares. Dal'Igna, Scherer e Silva (2020) afirmam que, nesse panorama, essas políticas constituem produtos da agenda global hegemônica liderada pela Organização para a Cooperação e o Desenvolvimento Econômico (OCDE) e pelo Banco Mundial. No Brasil, tanto os interesses do mercado quanto aqueles de determinados grupos religiosos - por meio de defesas como o Movimento Escola sem Partido (MESP) ${ }^{\mathrm{v}}$, por exemplo - conquistaram espaço no debate educacional. Assim, as autoras entendem que a BNCC e a BNCFP "atendem a um conjunto de interesses econômicos e religiosos que contribuem para modificar profundamente a formação docente brasileira e para intensificar as formas de controle e de regulação da docência” (p. 4).

Nesse cenário, o caráter democrático da BNCC e da BNCFP tem sido contestado por diversos autores. Sousa et al. (2020), por exemplo, argumentam que a presença de profissionais de Educação Básica na formulação da BNCC pode ser questionada por meio de pesquisas que apontam que essa participação não foi efetiva e teve como único objetivo endossar as concepções de educação já defendidas pelos atores da política. Para além da presença efetiva de atores privados na formulação da BNCC (MACEDO, 2014), o mesmo pode ser afirmado sobre a construção da BNCFP, a qual incluiu seis profissionais que "registram trajetórias marcadas por atuação na área da administração, da educação à distância e no setor empresarial e educacional privado" (FARIAS, 2019, p. 161) ${ }^{\mathrm{vi}}$.

De acordo com Farias (2019), outro aspecto consiste no caráter a "toque de caixa" sob o qual a BNCFP foi concebida, tendo sido encaminhada como um documento preliminar ao Conselho Nacional de Educação (CNE) em dezembro de 2018 e posteriormente recolhida pelo MEC. A autora identifica um caráter prematuro na própria Política Nacional de Formação de Professores (PNFP), da qual a BNCFP faz parte. Anunciada em outubro de 2017 e apresentada apenas por meio de slides, essa política não explicita de que forma irá dialogar com as Diretrizes Curriculares Nacionais para a formação docente estabelecidas pela Resolução 2/2015 do CNE (BRASIL, 2015). De acordo com diversos autores e entidades educacionais, ao contrário da 
BNCFP, tais diretrizes expressam um consenso alcançado por meio de um debate democrático que contou com ampla participação da sociedade em termos do que poderia e deveria ser valorizado como uma base comum para a formação de professores (SANTOS; DINIZPEREIRA, 2016; FARIAS, 2019).

De acordo com o documento preliminar, a BNCFP está organizada em três eixos conhecimento, prática e engajamento - para os quais são estabelecidas 12 competências específicas. Sobre o eixo da prática, são valorizadas:

1. Capacidade de planejar e de executar ações que resultem na efetiva aprendizagem dos estudantes; 2. Empenho para criar e gerir ambientes diversos de aprendizagem; 3. Capacidade para avaliar a aprendizagem; e 4 . Conduzir as práticas pedagógicas com vistas ao domínio das competências e das habilidades esperadas. (BRASIL, 2018, p. 50)

Como professores da educação básica e como formadores de futuros professores, compreendemos e defendemos a importância do planejamento, da didática e da avaliação, dimensões da prática docente mencionadas na passagem acima. No entanto, alguns aspectos desse trecho merecem destaque. Nos chama atenção, por exemplo, a relação linear de causa e efeito entre o planejamento e a didática docentes e a aprendizagem dos estudantes. Em seguida, o adjetivo "efetiva" indica que a aprendizagem deve ser avaliada e diagnosticada de maneira precisa. Esse sentido é retomado na terceira competência e direcionado, no quarto item, para determinadas habilidades, aquelas identificadas na BNCC - e nos livros didáticos atuais (GEWANDSZNAJDER; PACCA, 2018) - por códigos alfanuméricos.

A partir da experiência que relatamos no tópico anterior e das considerações feitas em seguida sobre a BNCFP, entendemos que o trecho destacado acima defende que a aprendizagem dos estudantes depende exclusivamente do planejamento, da didática e do empenho de seus professores, os quais devem se limitar às competências e habilidades dispostas na BNCC para que os alunos obtenham rendimentos elevados nas avaliações padronizadas às quais serão submetidos. Tal interpretação se aproxima à de Farias (2019), que identifica, na BNCFP, intensa responsabilização da escola e do professor, carência na valorização da autonomia e da criticidade docente e uma concepção de aprendizagem tornada sinônimo de desempenho. Assim, a BNCFP opera como:

Um script fechado, pois com uma lógica homogeneizante e focada nos resultados, que não deixa margem para pensar a formação para a docência numa perspectiva larga e que considere a complexidade do ensinar, a diversidade dos contextos de trabalho, a pluralidade social dos discentes com os quais o professor lida e, sobretudo, para promover um desenvolvimento que valorize efetivamente esse profissional. (FARIAS, 2019, p. 163) 
Indo além, na concepção de docência defendida pela BNCFP, o professor considerado engajado é aquele que usa técnicas de gestão para alcançar eficácia no resultado de seus estudantes e que apresenta graus de flexibilidade, dedicação e comprometimento intensos o suficiente para que, mesmo em condições de trabalho precarizadas, tal resultado possa ser alcançado. Neste raciocínio, o professor se torna submisso a uma cultura de prestação de contas, na qual ele não apenas é controlado para tal, como é instruído a desenvolver e cultivar o desejo de se manter responsável pelo desempenho elevado de seus estudantes nas avaliações padronizadas externas (DAL'IGNA; SCHERER; SILVA, 2020). Nesse ponto, entendemos que o ranqueamento relatado pelas professoras no tópico anterior opera como um dos mecanismos que visam sustentar esse dispositivo de (auto)controle.

\section{Caminhos para a formação docente}

Tendo discutido algumas implicações que classificamos como negativas para a docência e a formação docente, nesta seção iremos apontar alguns aspectos dos cursos de formação de professores que podem ser especialmente valorizados como forma de romper - mesmo que não totalmente - com o reducionismo técnico proposto pela BNCFP e pela BNCC. Cabe ressaltar que nossa intenção não é estabelecer uma nova lista de normas que definem o "bom professor" de acordo com a argumentação que construímos. Trata-se de reflexões desenvolvidas a partir da experiência que relatamos neste texto e das considerações da comunidade acadêmica a respeito da BNCFP.

Em primeiro lugar, é necessário explicitar nosso posicionamento contrário às políticas de padronização curricular promulgadas no Brasil na segunda metade da década - BNCC e BNCFP - em virtude dos diversos motivos desenvolvidos ao longo deste texto. Como formadores de professores que prezam pela autonomia docente, entendemos que, quando valorizada, essa autonomia possibilita o desenvolvimento de práticas pedagógicas nas quais tanto o professor quanto os estudantes se configuram como autores. Nesse sentido, compreendemos a pertinência de políticas curriculares - desde que formuladas com ampla participação da sociedade - para subsidiar essas autorias e fornecer condições para a socialização de conhecimentos diversos e para a mobilização e a construção das subjetividades de professores e estudantes, valorizando a pluralidade dos cotidianos escolares e entendendo a imprevisibilidade inerente a essa concepção de currículo e de educação.

Assim, em um cenário de regulação curricular e docente, defendemos a importância da construção de um senso de autoria curricular nos cursos de formação de professores, de modo que os licenciandos entendam que seus conhecimentos - específicos, pedagógicos e docentes 
(TARDIF, 2014) $)^{\text {vii }}$ - os capacitam a criar currículos diversos em seus cotidianos de atuação a partir das propostas curriculares que são disponibilizadas. A título de exemplo, considerando a expressiva redução da educação ambiental na BNCC na disciplina escolar Ciências (SILVA; LOUREIRO, 2019), é desejável um olhar autoral por meio do qual o professor realize seu planejamento e conduza sua didática de modo a dar conta das habilidades elencadas no documento e, ao mesmo tempo, de objetivos pedagógicos que considere escassos ou ausentes.

A argumentação de Certeau (2014) sobre as noções de estratégia e tática - que desenvolvemos anteriormente ao comentar sobre as ações das professoras da escola municipal - nos permitem embasar essa colocação de maneira mais sólida. A partir dos movimentos de tática durante o consumo das regras, os modos pelos quais os sentidos são ampliados dependem de diversos fatores, incluindo os sujeitos que habitam um determinado espaço-tempo. Assim, entendemos que, nos cursos de formação de professores, podemos trabalhar com a noção de que as políticas curriculares constituem regras que podem ser consumidas de forma criativa, gerando sentidos não previstos pela estratégia e que nos permitem incorporar objetivos pedagógicos não valorizados - ou mesmo resistidos - pelo atual contexto neoliberal e neoconservador.

O estudo de Carmo e Selles (2018) demonstra a potencialidade da argumentação de Certeau (2014) para a compreensão das inventividades cotidianas dos professores de Biologia. Pela combinação de diversos modos de fazer, os docentes traduzem seus saberes para a produção de um conhecimento escolar que favorece a aprendizagem de conteúdos biológicos. Os autores afirmam que, mesmo em práticas docentes que seguem um mesmo direcionamento ou material curricular, são observadas abordagens didáticas distintas, as quais constituem maestrias contingentes - e, portanto, não ensaiadas previamente - de cada professor. Tais maestrias resultam das táticas efetivadas por cada professor, as quais permitem a materialização de "inventividades, que resistem e se contrapõem às prescrições curriculares" (CARMO; SELLES, 2018, p. 296). A partir das reflexões que desenvolvemos neste texto, propomos que, além das maestrias não ensaiadas, sejam valorizadas aquelas que podem ser ensaiadas, sobretudo no âmbito do planejamento.

Considerando o cenário de regulação do trabalho docente imposto pela BNCC e BNCFP, assim como Vilela, Alves e Selles (2006), defendemos que um dos aspectos a serem valorizados na formação de professores é a construção de coletividades de professores e professoras que apreendam a dimensão política do fazer docente. Segundo as autoras, essas coletividades são edificadas no âmbito das relações estabelecidas entre os sujeitos que participam da formação inicial de professores durante a prática de ensino: licenciandos, 
professores regentes e professores da universidade. Para as autoras, as relações entre professores em formação e seus futuros pares se constituem como espaços de negociação capazes de assumir um caráter de resistência às imposições normativas.

Desse modo, argumentamos que uma formação docente pautada na construção coletiva e dialógica de práticas pedagógicas favorece a criação e a manutenção dessas coletividades que se materializam. Na possibilidade de os professores produzirem as inventividades que se contrapõem às prescrições curriculares, retomamos o exemplo da educação ambiental porque entendemos que as táticas ensaiadas com o objetivo de explicitar a dimensão sociopolítica do debate ambiental podem ser compartilhadas por meio de redes de coletividade docente. Essa mesma coletividade pode ser expandida para a construção e consolidação de espaços mais amplos de luta e resistência política a diferentes formas de controle do trabalho docente, tais como a BNCC e BNCFP.

Reconhecemos que, ao valorizarmos esses aspectos nos cursos de formação de professores, não podemos afirmar que estaremos possibilitando que, por meio da autoria curricular e de projetos de coletividade docente mais pontuais e/ou cotidianos, os futuros professores não estarão sujeitos ao controle. Em um contexto de crescente sofisticação do cerceamento da profissão docente, seria ingênuo de nossa parte fazer tal colocação, de modo que reconhecemos a necessidade de mobilizações mais amplas, como as de natureza sindical, as quais não foram objeto de reflexão deste texto. É precisamente no reconhecimento desses limites que entendemos que as considerações tecidas nesta seção ilustram a pertinência de leituras, discussões, trabalhos e atividades - tanto nas disciplinas pedagógicas quanto no estágio supervisionado - que visem sustentar uma autocompreensão dos licenciandos como futuros agentes de refração curricular.

Esta ideia do docente como agente de refração curricular deriva de estudos realizados no campo do Currículo por Goodson (2019). A partir de uma investigação sobre a incorporação de reformas curriculares neoliberais desde a década de 1990 em diversos países da Europa, o autor identifica diferenças em escalas nacionais, regionais e locais, as quais são explicadas por fatores de amplitudes diversas. Por exemplo, na Finlândia, onde tais políticas são menos intensas e a autonomia docente é socialmente valorizada, a reestruturação curricular acabou sendo ativamente contestada pelos professores. Por outro lado, na Inglaterra, país que lidera esses tipos de reforma desde o final da década de 1940, houve uma integração efetiva da centralização curricular e uma consequente remodelação dos profissionais da educação, os quais se adequaram a essas mudanças. 
Em uma primeira percepção, embora reconheçamos a enorme diferença entre os contextos educativos europeus citados e a nossa realidade, entendemos que essa comparação entre Finlândia e Inglaterra - ilustra o potencial e o limite da atuação do professor e dos fatores que a influenciam que estabelecemos no parágrafo anterior. Em outras palavras, em um país com regulação curricular menos intensa e autonomia docente historicamente presente, as possibilidades da autoria curricular são invariavelmente mais concretas.

\begin{abstract}
Mas não devemos, com isso, considerar que países reagem monoliticamente às iniciativas de reestruturação. Há uma variedade de "pontos de refração" ou membranas de meio social que as políticas de reestruturação devem atravessar: sistemas nacionais, sistemas regionais, sistemas de conselhos escolares - até mesmo escolas específicas e salas de aulas e professores individuais. Isso significa que um amplo espectro de reações é possível, mesmo que possamos destacar certas características nacionais de atuação. (GOODSON, 2019, p. 79, grifos nossos)
\end{abstract}

No conceito da Física mobilizado por Goodson (2019), o ângulo da refração - fenômeno no qual a luz muda de trajetória ao passar para um meio diferente - depende da densidade desse novo meio. Entendemos que as escolas não são meios estáticos e, nesse sentido, podem apresentar densidades diversas, pois dependem, em parte, das ações coletivas e individuais dos profissionais que nelas atuam, tanto nos conselhos escolares quanto nas salas de aula. Nesse sentido, valorizamos as possibilidades cotidianas das táticas docentes - coletivas e individuais, planejadas e não ensaiadas - em influenciar o ângulo assumido nessa refração, ou seja, os sentidos efetivados na encenação de políticas curriculares como a BNCC e a BNCFP. Daí a nossa aposta em atividades, no âmbito dos cursos de formação inicial e continuada, que promovam a autoidentificação - por licenciandos, docentes e formadores de professores - como agentes de refração curricular.

\title{
Considerações finais
}

Este texto buscou refletir sobre alguns desdobramentos da BNCC na atuação docente na educação básica e da BNCFP na formação de professores. As ações realizadas no contexto do projeto de extensão "Compartilhando Boas Práticas de Ensino de Ciências e Biologia entre Escolas Públicas" buscaram estreitar os diálogos com professoras atuantes na rede municipal e apontar possíveis caminhos cotidianos de apropriação e reformulação dessas políticas curriculares.

Ao levantarmos as questões e impressões colocadas pelas professoras participantes, fortalecemos a coletividade docente, produzindo conjuntamente o entendimento e a análise das implicações impostas pela BNCC no cotidiano das práticas docentes. As reflexões nos conduziram a elaborar aspectos que valorizamos na formação de professores: o entendimento 
dos licenciandos e dos professores como agentes de produção de conhecimento e de refração curricular; e a coletividade docente como uma rede que tanto potencializa a compreensão anterior quanto permite o engajamento político em uma escala mais ampla.

Por fim, ressaltamos que o próprio projeto "Compartilhando Boas Práticas de Ensino de Ciências e Biologia entre Escolas Públicas" e o Complexo de Formação de Professores da UFRJ adquirem grande potencialidade como espaços coletivos de produção de saberes e de reconhecimento da atuação docente como prática política e social. Constituem-se, assim, como iniciativas de fortalecimento e enfrentamento, formuladas por e para professores, visando a construção de uma educação pública e socialmente referenciada, necessária a uma sociedade justa e sustentável que há tempos desejamos.

\section{Referências}

BALL, Stephen John. Education Reform: A Critical and Post Structural Approach. Buckingham: Open University Press, 1994, 164 p.

BIONDO, Franco Gomes. Base Nacional Comum Curricular: contexto, significados e desalinhamentos cotidianos. e-Mosaicos, v. 8, n. 17, jan./abr. 2019, p. 19-33. Disponível em: $<$ www.e-publicacoes.uerj.br/index.php/e-mosaicos/issue/view/2019/showToc >. Acesso em 8 set. 2020 .

BORBA, Rodrigo Cerqueira do Nascimento Borba; ANDRADE, Maria Carolina Pires de; SELLES, Sandra Escovedo. Ensino de Ciências e Biologia e o cenário de restauração conservadora no Brasil: inquietações e reflexões. Revista Interinstitucional Artes de Educar, v. 5, n. 2, mai./ago. 2019, p. 144-162. Disponível em: <www.epublicacoes.uerj.br/index.php/riae/article/view/44845>. Acesso em 8 set. 2020.

BRASIL. Base Nacional Comum Curricular - Educação é a Base. MEC/CONSED/UNDIME, Brasília, 2018, p. 7-12, p. 321-330, p. 343-351. Disponível em: $<$ basenacionalcomum.mec.gov.br/images/BNCC_EI_EF_110518_versaofinal_site.pdf $>$. Acesso em 8 set. 2020.

BRASIL. Proposta para Base Nacional Comum da Formação de Professores da Educação Básica. MEC. Brasília, 2018. Disponível em:

<portal.mec.gov.br/index.php?option=com_docman\&view=download\&alias=105091-bncformacao-de-professores-v0\&category_slug=dezembro-2018-pdf\&Itemid $=30192>$. Acesso em: 8 set. 2020 .

BRASIL. Resolução CNE/CP 02/2015, de $1^{\circ}$ de julho de 2015. Define as Diretrizes Curriculares Nacionais para a formação inicial em nível superior (cursos de licenciatura, cursos de formação pedagógica para graduados e cursos de segunda licenciatura) e para a formação continuada. Diário Oficial da União, Brasília, 2 de julho de 2015. Disponível em: <portal.mec.gov.br/docman/agosto-2017-pdf/70431-res-cne-cp-002-03072015-pdf/file>. Acesso em 8 set. 2020.

CARMO, Edinaldo Medeiros; SELLES, Sandra Escovedo. "Modos de Fazer” Elaborados por Professores de Biologia como Produção de Conhecimento Escolar. Revista Brasileira de 
Pesquisa em Educação em Ciências, v. 18, n. 1, jan./abr. 2018, p. 269-299. Disponível em: <periodicos.ufmg.br/index.php/rbpec/issue/view/226>. Acesso em 8 set. 2019.

CERTEAU, Michel de. A invenção do cotidiano: artes de fazer. 22a Edição. Petrópolis: Vozes, 2014, p. 319.

DAL'IGNA, Maria Cláudia; SCHERER, Renata Porcher; SILVA, Miriã Zimmermmann da. Trabalho docente, gênero e políticas neoliberais e neoconservadoras: uma leitura crítica da Base Nacional Comum de formação de professores da Educação Básica. Práxis Educativa, v. 15, ago. 2020, p. 1-21. Disponível em:

<revistas2.uepg.br/index.php/praxiseducativa/issue/view/694>. Acesso em 8 set. 2020.

FARIAS, Isabel Maria Sabino de. O discurso curricular da proposta para BNC da formação de professores da educação básica. Retratos da Escola, Brasília, v. 13, n. 25, p. 155-168, jan./mai. 2019. Disponível em: <retratosdaescola.emnuvens.com.br/rde/issue/view/35>. Acesso em 8 set. 2020.

GABRIEL, Carmen Teresa. Complexo de Formação de Professores: uma experiência (inter)institucional em curso. Revista de Currículum y Formación del Profesorado, v. 23, n. 3, set. 2019, p. 189-209. Disponível em:

<recyt.fecyt.es/index.php/profesorado/article/view/74500>. Acesso em 30 set. 2020.

GEWANDSZNAJDER, Fernando; PACCA, Helena. Teláris Ciências, $6 o$ ano: Ensino Fundamental, Anos Finais. 3a Edição. São Paulo: Ática, 2018, 256 p.

GOODSON, Ivor Frederick. Currículo, narrativa pessoal e futuro social. Campinas: Editora da Unicamp, 2019, 295 p.

LEHER, Roberto. Autonomia universitária e liberdade acadêmica. Revista Contemporânea de Educação, v. 14, n. 29, jan/abr. 2019, p. 208-226. Disponível em:

<revistas.ufrj.br/index.php/rce/article/view/23167>. Acesso em 23 set. 2020.

LORDÊLO, José Albertino Carvalho; ROSA, Dora Leal; SANTANA, Lisa de Almeida. Avaliação processual da aprendizagem e regulação pedagógica no Brasil: implicações no cotidiano docente. FACED, n. 17, jan/jun. 2010 p. 13-33. Disponível em:

<cienciasmedicasbiologicas.ufba.br/index.php/entreideias/article/download/4555/3806>. Acesso em 28 set. 2020.

MACEDO, Elizabeth. Base nacional curricular comum: novas formas de sociabilidade produzindo sentidos para educação. e-Curriculum, v. 12, n. 3, out./dez. 2014, p. 1530-1555. Disponível em: <revistas.pucsp.br/curriculum/issue/view/1331>. Acesso em 8 set. 2020.

MAINARDES, Jefferson. Abordagem do ciclo de políticas: uma contribuição para a análise de políticas educacionais. Educação \& Sociedade, v. 27, n. 94, jan./abr. 2006, p. 47-69. Disponível em: <doi.org/10.1590/S0101-73302006000100003>. Acesso em 8 set. 2020.

NÓVOA, António. Relatório Final: um novo modelo institucional para a formação de professores na Universidade Federal do Rio de Janeiro, 2017, 30 p. Disponível em: <projetos.macae.ufrj.br/portalcfp/wp-content/uploads/2020/05/Um-novo-modeloInstitucional-para-a-Formac $\% \mathrm{CC} \% \mathrm{~A} 7 \mathrm{a} \% \mathrm{CC} \% 830-d e-P r o f e s s o r e s-n a-U F R J . p d f>$. Acesso em 23 set. 2020.

SANTOS, Lucíola Licínio de Castro Paixão; DINIZ-PEREIRA, Júlio Emílio. Tentativas de padronização do currículo e da formação de professores no Brasil. Caderno Cedes, v. 36, n. 100, 2016, p. 281-300. Disponível em: <doi.org/10.1590/cc0101-32622016171703>. Acesso em 8 set. 2020. 
SAVIANI, Dermeval. Sistema Nacional de Educação e Plano Nacional de Educação: significados, controvérsias e perspectivas. Campinas: Autores Associados, 2014, 176 p.

SILVA, Silvana do Nascimento; LOUREIRO, Carlos Frederico. O sequestro da Educação Ambiental na BNCC (Educação Infantil - Ensino Fundamental): os temas

Sustentabilidade/Sustentável a partir da Agenda 2030. In: Anais do XII Encontro Nacional de Pesquisa em Educação em Ciências - XII ENPEC. Natal, jun. 2019, 7 p. Disponível em: $<$ abrapecnet.org.br/enpec/xii-enpec/anais/resumos/1/R0724-1.pdf>. Acesso em 8 set. 2020.

SOUSA, Francisca Genifer Andrade de; FREIRE, Vitória Chérida Costa; BENVINDO DOS SANTOS, Francisca Mayane; FERNANDES, Francisca Risolene. Possíveis implicações da Base Nacional Comum Curricular para a formação dos professores da Educação Básica. Revista de Instrumentos, Modelos e Políticas em Avaliação Educacional, v. 1, n. 1, jan./abr. 2020, 15 p. Disponível em: <revistas.uece.br/index.php/impa/issue/view/257>. Acesso em 8 set. 2020.

TARDIF, Maurice. Saberes docentes e formação profissional. $7^{\text {a }}$ Edição. Petrópolis: Vozes, 2014, 328 p.

UNIVERSIDADE FEDERAL DO RIO DE JANEIRO, Conselho Universitário. Resolução 20/2018. Aprova o Regimento do Complexo de Formação de Professores da Universidade Federal do Rio de Janeiro. Boletim da Universidade Federal do Rio de Janeiro, Rio de Janeiro, 2018, 6 p. Disponível em:

<consuni.ufrj.br/images/Resolucoes/Resolucao_n_20_de_2018.pdf>. Acesso em 8 set. 2020.

VILELA, Mariana Lima; AYRES, Ana Cléa Moreira; SELLES, Sandra Escovedo. A constituição de coletividades docentes como possibilidade formativa na Prática de Ensino de Ciências Biológicas. In: Anais do XIII ENDIPE - Encontro Nacional de Didática e Prática de Ensino. Recife, UFPE, 2006.

\footnotetext{
${ }^{i}$ Disponível em: https://gestaoescolar.org.br/conteudo/2268/bncc-os-desafios-para-2019-e-2020. Acesso em 26 de maio de 2021.

ii Neste texto, evitamos o uso da palavra "implementação" porque, apesar dos mecanismos de controle docente e curricular valorizados pela BNCC, entendemos, a partir dos estudos de Stephen Ball, que as políticas "não dizem o que você deve fazer, elas criam circunstâncias nas quais o leque de opções disponiveis para decidir o que fazer é reduzido ou alterado, ou são definidos objetivos e resultados específicos" (BALL, 1994, p. 19, tradução livre). Assim, a partir de palavras como "encenação" - proposta pelo próprio autor ("enactment") - e "efetivação", procuramos contemplar os "processos de resistência, acomodações, subterfúgios e conformismo dentro e entre as arenas da prática” (MAINARDES, 2006, p. 50).

iii Fazemos referência às avaliações padronizadas, aplicadas periodicamente e cuja formulação não conta com a participação das professoras, como a Prova Brasil, no âmbito do Sistema de Avaliação da Educação Básica (SAEB).

iv De acordo com Lordêlo, Rosa e Santana (2010), a avaliação processual ocorre ao longo do processo educativo para que se conheça o que cada estudante já aprendeu e aquilo que ainda necessita de consolidação, de modo a orientar aluno e professor a respeito do caminho a ser percorrido dali em diante. Apresenta, assim, uma função formativa e não tem como objetivo atribuir notas ou conceitos.

${ }^{v}$ O MESP foi criado em 2004 pelo advogado Miguel Nagib para combater uma suposta doutrinação política e ideológica nas escolas. Apesar de ter tido suas atividades encerradas em 2019 e de Nagib ter anunciado sua retirada do movimento também em 2019, o MESP criou defesas como a omissão das discussões de gênero e de conteúdos ligados à evolução biológica (BORBA; ANDRADE; SELLES, 2019), estimulando a elaboração de leis em diferentes municípios brasileiros nessa perspectiva.
} 


\footnotetext{
vi Maria Alice Carraturi Pereira (Hélade Consultoria em Educação), Guiomar Namo de Mello (Fundação Victor Civita), Bruna Henrique Caruso (SEB/MEC), Fernando Luiz Abrucio (FGV), Catarina Ianni Segatto (Eaesp/CEAPG) e Lara Elena Ramos Simielli (Eaesp/FGV) (FARIAS, 2019).

${ }^{\text {vii }}$ De acordo com Tardif (2014), os saberes específicos compreendem aqueles do âmbito da área de formação, como Biologia, Química e Física. Os saberes pedagógicos derivam das disciplinas de Educação, como Psicologia da Educação e Sociologia da Educação. Por fim, os saberes docentes se referem aos conhecimentos produzidos no contexto da prática, no qual cada professor vai tecendo suas reflexões e respostas para os diversos desafios que se materializam nos cotidianos escolares.
} 